\title{
Generative Critique in Interdisciplinary Collaborations: From Critique in and of the Neurosciences to Socio-Technical Integration Research as a Practice of Critique in $\mathbf{R}(\mathbf{R}) \mathbf{I}$
}

\author{
Mareike Smolka (1) \\ Received: 20 February 2019 / Accepted: 27 December 2019 /Published online: 30 January 2020 \\ (C) The Author(s) 2020
}

\begin{abstract}
Discourses on Responsible Innovation and Responsible Research and Innovation, in short R(R)I, have revolved around but not elaborated on the notion of critique. In this article, generative critique is introduced to $\mathrm{R}(\mathrm{R}) \mathrm{I}$ as a practice that sits in-between adversarial armchair critique and co-opted, uncritical service. How to position oneself and be positioned on this spectrum has puzzled humanities scholars and social scientists who engage in interdisciplinary collaborations with scientists, engineers, and other professionals. Recently, generative critique has been presented as a solution to the puzzle in interdisciplinary collaborations on neuroscientific experiments. Generative critique seeks to create connections across disciplines that help remake seemingly stable objects in moments when taken-forgranted ways of seeing and approaching objects are unsettled. In order to translate generative critique from the neurosciences to $R(R) I$, socio-technical integration research (STIR) is proposed as a practice of generative critique in interdisciplinary $\mathrm{R}(\mathrm{R}) \mathrm{I}$ collaborations. These collaborations aim to account for societal aspects in research and technology development. For this purpose, a variety of approaches have been developed, including STIR and video-reflexive ethnography (VRE). STIR and VRE resemble each other but diverge on affective, collaborative, and temporal dimensions. Their juxtaposition serves to develop suggestions for how STIR could
\end{abstract}

\footnotetext{
M. Smolka ( $\bowtie)$

Faculty of Arts and Social Sciences, University Maastricht, Grote Gracht 90-92, 6211SZ Maastricht, Netherlands

e-mail: m.smolka@maastrichtuniversity.nl
}

be modified on these dimensions to better enact generative critique in interdisciplinary $\mathrm{R}(\mathrm{R}) \mathrm{I}$ collaborations. In this way, the article contributes to ongoing discussions in $R(R) I$ and in the engaged programme in science and technology studies more broadly on the dynamics of positioning in collaborative work.

Keywords Interdisciplinarity. Cross-disciplinarity . Collaboration - Socio-technical integration research . Generative critique $\cdot$ Critical Neuroscience

\section{Introduction}

The notion of critique has remained underdeveloped in interrelated discourses on Responsible Innovation (RI) and Responsible Research and Innovation (RRI). Whereas the former has strong US policy and academic roots, the latter emerged as a policy discourse from the European Commission's Science in Society programme $[1,2]$. Both discourses speak to the integration of societal concerns and needs into research and technology development processes [3-5]. This agenda has been related in different manners to critique in $R(R) I$. Van Lente et al.'s recent paper on 'Responsible innovation as a critique of technology assessment' [6] sparked discussions in $\mathrm{R}(\mathrm{R}) \mathrm{I}$ communities before it was published. Heated discussions have also revolved around the claim that $R(R) I$ is itself in need of critique $[7,8]$, especially in light of forecasts of 'the end of RRI' ([9], p. 253) due to difficulties of putting it into practice [10-13]. Some sceptics consider $\mathrm{R}(\mathrm{R}) \mathrm{I}$ as an immunisation against 
public critique of science and innovation $[14,15]$. Proponents, by contrast, regard $R(R) I$ as full of potential 'to provide an effective conduit for criticisms and the input of critical thinking and reflexivity into science and innovation' ([16], p. 64; see also [1]). Along these lines, some contributors to the proceedings on the Dutch RI conference series have referred to $\mathrm{R}(\mathrm{R}) \mathrm{I}$ as partly a 'critical analysis' ([17], p. 89; [18], p. 71) and 'critical reflection' ([19], p. 357) on scientific practices, assumptions, and knowledge [20,21]. What these different takes on the relation between $\mathrm{R}(\mathrm{R}) \mathrm{I}$ and critique have in common is that they are prevalent in $\mathrm{R}(\mathrm{R}) \mathrm{I}$ discourses, but do not specify critique.

Attempts to translate the conception of $R(R) I$ as a critique of science and technology development into practice have been made by humanities scholars and social scientists in interdisciplinary $\mathrm{R}(\mathrm{R}) \mathrm{I}$ collaborations with scientists, engineers, and other professionals. Different forms of such collaborations have been developed (e.g. Human Practices, Socio-Technical Integration Research, Toolbox Project, Value Sensitive Design). According to Fisher et al., they have three features in common [22]. First, they connect scholars and researchers across socio-technical divides. Second, collaborators work in close proximity, usually by involving a humanities scholar or social scientist in a technoscientific space. Third, they combine knowledge production about technoscientific practices with contribution to change in how technoscientific practitioners identify and engage with socio-ethical dimensions of their work. However, such collaborations are widely acknowledged to face challenges [23-30]. One of the challenges refers to the maintenance of a 'critical' position while being immersed in technoscientific practices.

Social scientists and humanities scholars who report on this challenge in interdisciplinary $R(R) I$ collaborations shed light on a dual concern. On the one hand, they are worried that they cannot contribute to technoscientific practices because they are perceived as adverse critical observers whose critique is detached from what matters for technoscientific practitioners. On the other hand, they fear losing critical distance and turning into uncritical research assistants. Viseu reports from her experience as an 'in-house social scientist' ([29], p. 643) at the Cornell NanoScale Facility that her contributions were often read as 'critical, adversarial, or ungrateful' ([29], p. 657). Referring to her expertise seemed to add 'unnecessary and unwelcome complexity to nanotechnology' ([29], p. 653) and created distance to her colleagues. Aircardi et al.'s reflections on their ongoing involvement in the Ethics and Society Subproject of the Human Brain Project reveal that they were concerned about their work being reduced to ethics management. 'It was important to be clear that we were not there to do the ethics for them' ([23], p. 15); they state to counter associations of their role with service.

Uncritical service and critique that fails to address the issues at hand sit at opposite ends of a spectrum in the middle of which humanities scholars and social scientists who pursue an 'engaged program[me]' try to position themselves ([31], p. 13). The engaged programme in science and technology studies (STS) bridges normative and theoretical agendas. It captures the overlap between what used to be distinguished as High Church STS aimed at knowledge production and rather activist Low Church STS $[32,33]$. For many STS researchers, understanding the social nature of science and technology is continuous with promoting socially responsible science. Whereas modest versions of the engaged programme address issues that are politically topical, stronger versions, such as action-oriented science studies [34], interactive social science [35], or engagement research [36], involve active engagement in the fields under study. Researchers who pursue the stronger version of the engaged programme have addressed the challenging dynamics of positioning themselves in collaborative work so as to navigate between armchair critique and loss of critical distance. Examples are collaborative projects with businesses [37], healthcare [38, 39], forensic pathology [40], ICT design [41], or scientific laboratories [25]. ${ }^{1}$

Neuroscientific laboratories, in particular, have opened their doors to invite humanities sch0olars and social scientists. They have welcomed those aspiring to observe neuroscientists for critically deconstructing neuroscientific practices [43] and those in pursuit of an engaged form of critique [44]. Some engaged forms of critique emerged in interdisciplinary collaborations on neuroscientific experiments, in which humanities scholars and social scientists managed to walk the middle path between overly detached critique and uncritical research assistance [45-48]. Anthropologist Niewöhner refers to this middle path as a 'generative mode of critique' ([49], p. 13). Borrowing from the work of Verran [50], he introduces generative critique as 'providing different problematisations and different questions' that may become 'generatively irritating when

\footnotetext{
${ }^{1}$ For a genealogy, see Zuiderent-Jerak [42].
} 
taken back to their respective thought collectives or epistemic cultures' ([49], p. 18). As a result, generative critique opens up possibilities for change in thought and practice by unsettling taken-for-granted disciplinary assumptions. Unsettlement of what seems to be stable opens possibilities to draw connections across disciplines when approaching an object from points of departure in the neurosciences, humanities, and social sciences.

Drawing on insights from generative critique in neuroscientific experiments, this article develops an approach to enact generative critique in interdisciplinary R(R)I collaborations. For this purpose, it addresses the following questions: (1) What is generative critique? (2) How is generative critique enacted in interdisciplinary collaborations between humanities scholars, social scientists, and neuroscientists? (3) How can generative critique be enacted in interdisciplinary $\mathrm{R}(\mathrm{R}) \mathrm{I}$ collaborations? The tripartite structure of this article follows these questions to flesh out a particular notion of critique for $\mathrm{R}(\mathrm{R}) \mathrm{I}$ discourses. This critique serves as a practice for social scientists and humanities scholars who pursue interdisciplinary $\mathrm{R}(\mathrm{R}) \mathrm{I}$ collaborations to position themselves in-between armchair critique and loss of critical distance. In this way, the article contributes to ongoing discussions in $\mathrm{R}(\mathrm{R}) \mathrm{I}$ and in the engaged programme in STS on the dynamics of positioning in collaborative work.

In the first section of the article, generative critique is developed by drawing on Verran and later work that applies generative critique in the context of interdisciplinary collaborations $[49,51]$. The second section shows how generative critique has been enacted in the neurosciences and how it paves a middle way between overly detached, deconstructive critique and overly attached, uncritical service. All three positions are laid out, and examples illustrate how critique has been enacted of and in the neurosciences. The verb 'to enact' highlights that critique is understood as a practice [52]. ${ }^{2}$ The operation of generative critique in the neurosciences serves as an inspiration for enacting generative critique in $\mathrm{R}(\mathrm{R}) \mathrm{I}$. Practices for enacting generative critique in interdisciplinary $\mathrm{R}(\mathrm{R}) \mathrm{I}$ collaborations are introduced in the third section. These practices are wellestablished approaches to engagement research: sociotechnical integration research (STIR) and video-

\footnotetext{
$\overline{2}$ On the complex history of critique as a concept, see De Boer and Sonderegger [53] or Gasché [54].
}

reflexive ethnography (VRE). Both STIR $[55,56]$ and $\operatorname{VRE}[57,58]$ are characterised by collaborative inquiry into practices, decisions, and underlying attitudes of day-to-day work in research and technology development (STIR) and in healthcare (VRE). STIR is juxtaposed with VRE to make suggestions for how STIR could learn from VRE so as to better facilitate generative critique. An empirical project that is currently in progress and implements the proposal of this article is outlined in the conclusion.

\section{Generative Critique}

In Science and an African Logic, historian and philosopher of science Verran introduces 'generative critique' ([50], p. 21) in order to move away from her initial conclusions about her fieldwork observations in Nigeria. From 1979 to 1986, Verran lived and worked in IleIfe where she taught and supervised science teachers in primary school education. Based on observations in Nigerian (Yoruba) classrooms, she concluded that logic and math were culturally relative and that an incommensurability separated 'Western' and 'other' knowledges. However, she was unable to finish her initial manuscript, for she felt that it 'failed to deliver a useful critique' ([50], p. 20). Instead of positioning herself as a removed observer who writes about communities in which Western knowledge had threatened other ways of knowing, she revised her manuscript so as to write for those she studied. ${ }^{3}$ To develop a critique that is useful for a bilingual community that struggles with tensions between Yoruba and Western math in everyday life, Verran paid continuous attention to what enabled and foreclosed the recognition of differences to the hegemonial. When colonial relations define which knowledge practices are legitimate, a 'generative critique' points at how communities with a colonial past stay with differences by bringing the hegemonic and the non-hegemonic together. An example is teaching how to measure body height as an extension (Western math) and as a multiplicity (Yoruba math) at the same time by making extension contingent on multiplicity. This involves asking pupils to extend a string from head to ground, wind it around a card that is $10-\mathrm{cm}$ wide, count the number of windings, multiply by ten, and add the

\footnotetext{
${ }^{3}$ On the politics of anthropological studies on the heritage of colonialism, see Pels [59].
} 
remaining centimetres of string to the product [60]. The example illustrates generative critique as a practice that enacts what might appear as stable objects, such as measuring body height, in different ways. A critique that remakes objects springs from creative ways to deal with tensions between different ways of seeing and approaching the world. To detect such tensions in everyday life that may allow for alternative ways of acting, Verran suggests to pay attention to 'disconcertment', a fairly common but often overlooked 'fleeting experience' ([50], p. 5). It occurs when encountering interruptions that do not fit one's line of reasoning. Due to their disruptive qualities, disconcerting moments provide 'a sure guide ... in generating possibilities for new futures' and, thus, an opening 'to do useful critique' ([50], p. 5).

Hillersdal et al. demonstrate how attention to disconcertment enables generative critique outside of postcolonial contexts [51]. The anthropologists pursued generative critique in Western interdisciplinary research projects on obesity and high levels of cholesterol in the blood. They report that 'sensitivity to difference, as when sharing doubts with project colleagues about how to approach a research problem, is a promising starting point for pursuing a generative critique' ([51], p. 3). Sensitivity for the experience of disconcertment helped Hillersdal and colleagues identify and work through moments in which the object under study was something else for collaborators from different disciplines. Generative critique is making connections between multiplicities of the same object, such as pain as an intensity located in an individual body and pain as formed in relation to others. ${ }^{4}$ These connections gave rise to new questions, such as what and how to advise people on choosing cholesterol-lowering drugs. Such questions also destabilised routine practices, economic and politically strategic agendas, as well as expertise and evidence hierarchies. Critique of the status quo was generative of 'other ways of "seeing and doing" problems' ([51], p. 3) because it was enacted in moments of collaboration when problem-solving was unsettled for and reconfigured with all parties.

According to Niewöhner, generative critique has also emerged in recent collaborations on laboratory experiments across the humanities, social sciences, and

\footnotetext{
${ }^{4}$ Kenney elaborates on the relations between Verran's generative critique and Mol's praxiography [61], a research methodology and genre of storytelling that foregrounds relations so that objects cease to be singular, abstract, or absolute and become multiple, material, and mutable [62].
}

neurosciences ([49], p. 17, and footnote 71). Strictly speaking, Niewöhner argues that generative critique depends on 'co-laboration' ([49], p. 10). He admits that the distinction between 'co-laboration' and 'collaboration' may be futile because the latter expression has been used with many different meanings in a variety of contexts. Therefore, 'collaboration' will be used in this article while presuming that generative critique is only possible in a collaboration that is co-laborative. Whereas collaboration usually rests on a shared political or institutional objective, co-laboration is a shared process of epistemic labour, 'experimenting with different ways of seeing-and-being-in-the-world' ([49], p. 10). Even though co-laboration does not aim at producing shared outcomes, 'there is the hope that the participating fields may change for the better in the sense that the colaborative effort will lead to something that can be taken back to their discipline' ([49], p. 18). Critique within colaboration is generative of possibilities for change. Generative critique does not depend on the ability to stand back for revealing the contingency of objects but operates from within co-laborative practices. Drawing on Verran, Niewöhner states that generative critique puts into question how objects have come into being and how and why they remain stable. Such questions can arise when people are brought together who are usually situated differently in relation to an object and, therefore, see and enact the same object differently. When these people co-laborate, they can make connections between these multiple objects, remake objects in new ways, and generate alternatives to what is hegemonic in their situated location. According to Niewöhner, humanities scholars and social scientists who enact generative critique resist the temptations to either loosen their critical grip because of co-opting relationships or to drift off to an 'epistemological meta-level'. He describes the latter mode of critique as 'ill-suited for co-laborative work, because co-laboration with fields requires operating closely to the relevances and logics of these fields rather than starting from an outright negation of these aspects' ([49], p. 13).

The three modes of critique-generative critique, loss of critical distance, and armchair critique-have structured the landscape of critique of and in the neurosciences [46]. In the following, this landscape will be sketched in order to create a template for critique in $\mathrm{R}(\mathrm{R}) \mathrm{I}$. The neurosciences serve as a case study, an exemplary illustration, that renders the three rather abstract modes of critique more concrete by discussing 
them within a specific context [63]. The neurosciences are selected as a case because critique of and in the neurosciences is considered to be representative of modes of critique prevalent but unspecified in $R(R) I$. Historian and philosopher of science Borck regards critique of the neurosciences as an example of $R(R) I$ 'avant la lettre' ([14], p. 243) because both discourses combine interdisciplinarity with the ambition to intervene in research processes so as to adjust them from within. Over the last five years, critique has become generative in interdisciplinary collaborations in the neurosciences. By contrast, humanities scholars and social scientists involved in interdisciplinary $\mathrm{R}(\mathrm{R}) \mathrm{I}$ collaborations still seem to aspire for such a form of critique. Therefore, the neurosciences could provide lessons for $\mathrm{R}(\mathrm{R}) \mathrm{I}$ to carve out notions of critique, first and foremost generative critique.

\section{Critique of and in the Neurosciences}

The neurosciences are a conglomerate of various disciplines: neuroanatomy, neurophysiology, molecular neurobiology, neuropharmacology, and cognitive neuroscience, to name but a few. Although the brain is the centre of attention, these disciplines study the human nervous system which includes the spinal cord and elements of the peripheral nervous system, a network that transfers information about the external and internal bodily environment back to the brain. Speaking of the neurosciences in plural reminds us that the field incorporates a huge range of methods and foci encompassing structural, functional, developmental, evolutionary, molecular, cellular, and computational studies [64]. Critical voices in the neurosciences complain that these approaches lack a unifying theory within which diverse findings could be integrated. For instance, the terms learning and memory are used across a range of disciplines ranging from cognitive neuroscience to molecular genetics, but do not necessarily refer to the same phenomena [65]. According to neurobiologist Rose, the lack of a unifying theory is partially disguised by a generally shared commitment to reductionism. It assumes that the mind can be reduced to the brain - the key to understanding 'who we really are' [66].

Reductionism has been at the centre of much backlash against the neurosciences' promises of scientific breakthroughs that constantly require 'money to be burned on a massive scale' but cannot be expected soon
([67], p. 3). Laments over neuroscientific hypotheses that posit brains as causes for social inequalities instead of social, political, and economic contexts must be situated in a broader discontent in the humanities and social sciences. Many facets of human life that were studied for most of the twentieth century through the lenses of 'culture', 'identity', 'society', and 'economy' have increasingly come to be understood as cerebral functions [68, 69]. The hegemonic neuroscientific discourse about human affairs does not only rob the humanities and social sciences of their subject matters but has worrisome societal consequences. Research in support of hypotheses that postulate depression as a brain disorder shapes subjectivities. Dumit argues that labels attributed to brain images, such as 'depressed' or 'normal', are 'incorporated into further experiments, patients' lives, and everyday notions of personhood' ([70], p. 11). Labelled images produce 'depressed' subjectivities, although one may question the criteria used to select individuals as 'depressed', the variation in images of 'depressed' people, and the technological contingency of image production.

Concerns about uncritical use of imaging technology, flawed statistical analyses, standpoint-specific biases, and other issues have fuelled critique both inside and outside of the neurosciences. A Nature publication entitled 'Brain imaging studies under fire: social neuroscientists criticised for exaggerating links between brain activity and emotions' [71] turned discussions among neuroscientists on dubious statistical analysis procedures into a public event of intra-scientific methodological critique [14]. Critique that goes beyond calls for rethinking scientific routines but questions fundamental epistemological assumptions has been put forward by feminist neuroscientists. Examples are studies by Joel who systematically debunks the assumption that sex exists as a dichotomous, biological variable in human brains [72-74]. In addition to neuroscientists' self-critique, humanities scholars and social scientists have engaged critically with the neurosciences. Drawing on Fitzgerald and Callard's modes of engagement [46] and Barry et al.'s modes of interdisciplinarity [75], three modes of critique are introduced. These modes of critique are placed on a spectrum, ranging from critique that is overtly removed from neuroscientific day-to-day research to a loss of critical capacity on the side of humanities scholars and social scientists. Generative critique sits in-between the two extremes of a spectrum; it is a critique that is enacted in collaboratively conducted experiments [49]. 


\section{Armchair Critique}

According to Fitzgerald and Callard, critique is the most common mode of humanities and social science engagement with the neurosciences [46]. They present a range of authors that have published historical, social, and cultural analyses to uncover biases in relation to social, political, economic, and epistemic interests and to deflate particular neuroscientific trends or claims. As these authors seek dialogue with the neurosciences but aim for dissensus and opposition to change the status quo, their relation to existing forms of neuroscientific theory and practice may be described as 'agonistic-antagonistic' ([75], p. 29). This relation has been established in five collections and books of critical scholarship published between 2011 and 2013 [76-80]. In one of these collections, humanities scholars and social scientists joined forces and explicitly concentrated their enterprise on the qualifier 'critical' [76].

The 'critical' in the name of the Critical Neuroscience initiative preserves 'historical solidarity' ([81], p. 362) with Frankfurt School critical theory. It shares with it a historico-political mission: to reveal the integrated system of leading assumptions, underlying normativities, material conditions, and social implications of scientific inquiry into human reality. By spelling out whose interests shape scientific research, critical theorists generate insights that allow them and others to change reality, to render reality less unjust [82]. In a similar vein, promoters of Critical Neuroscience follow a dual strategy. On the one hand, they pursue 'a multi-dimensional critical investigation of neuroscience-in-context' ([83], p. 13) that reckons ideological influences, biases, as well as hidden political and economic entanglements of neuroscientific assumptions. This agenda has been realised in studies that point to the seductive charm of brain images as direct representations of disease, difference, and personhood [84], the troubling relationship between management techniques and neuroscientific findings [85], the neurobiologisation of crime [86], and the burgeoning relations between national security industries and neuroscience research [87]. On the other hand, they call for adopting 'a hands-on approach that embeds and involves the critic within interdisciplinary research' ([83], p. 13). The objective is to render critique meaningful and productive for neuroscientific research.

However, Critical Neuroscience has shown hesitation to realise the proclaimed 'hands-on approach'. Fitzgerald et al. assert that Critical Neuroscience has resorted to armchair critique [88], instead of 'linking critique with lab practice to influence the shape of future research in neuroscience' ([86], p. 74). Most of the members of the initiative have not engaged with neuroscientists in experimental research, possibly because their mission is to reposition experiments in their 'context' ([89], p. 35). They use context as a knife that cuts through the black box of experimentation, allowing experimenters to see the ideological assumptions that inform their production and dissemination of knowledge. However, if the main weapon is a knife, there may be no experiment left after it has been sliced up into pieces. Neuroscientists are left empty-handed, deprived of material that they could either rethink and improve or contribute to an interdisciplinary project. Such rather destructive armchair critique has pervaded early critical scholarship on the neurosciences, which is why reviewers from the neurosciences have argued that despite calls for interdisciplinarity, 'bidirectional feedback is hardly found' ([90], p. 82). After reading Ortega and Vidal's Neurocultures [79], neuroscientist Mòdol i Vidal concludes:

$[\mathrm{N}]$ euroscience does not treat social issues (at least with a social approximation, leaving its own 'reductionist' perspective) and social [research] does not make research in the neurosciences (such as 'neuroscientist[s]'). There is probably, where the problem lies. ([90], p. 82)

In order to overcome this problem, Fitzgerald et al. suggest that "it may be "experiment", and not "[social] context", that forms the meeting-ground between neuro-biological and socio-political research practices' ([88], p. 1). Such suggestions have also been raised in recently published scholarship that has continued the critical trajectory [91-93]. Whereas the Critical Neuroscience initiative has dissolved because members moved on to other projects [14], their critical successors rethink the relation between the neurosciences and the humanities. Several contributions to Leefmann and Hildt's collection discuss possible forms of 'multidirectional' ([94], p. xii) interactions between the neurosciences, social sciences, and humanities. In this spirit, De Vos and Pluth include three essays of researchers working in the neurosciences in their volume ([91], p. 2). Critics seem to start leaving their armchairs to enter laboratories and initiate collaborations with neuroscientists. 


\section{Loss of Critical Distance}

Calls for interdisciplinary collaboration are often accompanied by worries among humanities scholars and social scientists about a loss of critical distance due to cooptation. Such loss of critical distance can take two forms: 'ebullience' ([46], p. 11) or 'service-subordination' ([75], p. 28). Ebullience refers to uncritical incorporation of neuroscientific claims in scholarship in support of theoretical insights of cultural and social analyses. An example is work on affect theory in cultural studies that often rests on 'surprisingly thin, often naïve, summaries' ([46], p. 11) of neuroscientific studies, such as Massumi's 'The Autonomy of Affect' [95]. Similarly uncritical are scholars whose collaborations with neuroscientists are characterised by a hierarchical division of labour. A 'service discipline' ([75], p. 29), often from the humanities and social sciences, adopts a natural science definition of a problem and supports the development of solution strategies. Service may also consist in assessing and generating public understanding of the 'master' science ([75], p. 29).

Fear to be reduced to a neuroscientist's 'handmaid' has been prevalent in several humanities-neuroscience collaborations. Lysen's analysis of recent work by artist Antye Guenther and neuroscientist Alexander Sack in the Brain Stimulation and Cognition group of University Maastricht suggests potentially conflicting interests in an art-science collaboration [96]. Sack's research group studies non-invasive brain stimulation to gain a better understanding of neural mechanisms underlying perception, cognition, and behaviour. The group faces difficulties to visualise complex, dynamic patterns of neuronal activity on which their research is premised. Though the question of (the impossibility of) visualisation had sparked Sack's initial interest in engaging in an art-science project, this approach quickly appeared not to be satisfactory. With Guenther's insistence, both agreed 'an interesting artscience project would need to steer away from the tendency to assign the artist the (instrumental) role of visualizing science "post-closure" ([96], p. 66, emphasis in original). An instrumental role would deprive Guenther of her critical capacity to question the epistemology of experimentation and the ability to define key issues for investigation during her visits of the research group. Klein and Marghetis suggest even wider implications of such a division of labour, which they have observed in many collaborations between performers or performance scholars and cognitive neuroscientists [97]. Much of this collaborative work is framed as a 'friendly symbiosis' ([98], p. xiv; see also [99]). According to Klein and Marghetis,

[t]his symbiosis is enacted largely as an exchange, whereby science provides frameworks, paradigms, and authoritative weight, and performance provides vivid and visceral materiality. This has two related implications: the bodies and practices of science disappear, while the embodied knowledge of performance continues to be institutionally undervalued. ([97], p. 35, emphasis in original)

Performance and performers are reduced to mute material and lose their avant-garde critical function of disruption that reveals and critiques aesthetic, social, and political norms.

The possibility of losing critical capacity may also be the reason why Critical Neuroscience has not lent a hand to neuroscientists in the laboratory. Calls for 'critical friendship between human sciences and neurosciences' ([80], p. 3) or for 'transdisciplinarity' that draws on a 'spirit of good communication' ([100], p. 16) run the risk of 'fabric softening' according to Jan Slaby who has been a driving force behind the Critical Neuroscience initiative (e-mail communication, October 8, 2017). 'Good communication' may easily convert into what Fitzgerald et al. call "'equivocal speech"- - mode that is attentive to the things that are better left unsaid' ([47], p. 716), such as critical comments that could jeopardise the publication of a shared result. In order to guard against silence or moderation of critical voices, Slaby urged the Critical Neuroscience initiative to remain critical in two respects (e-mail communication, October 8, 2017). First, it must trace the entanglement of any neuroscientific project with neoliberal interests and capitalism (cf. [101]) to counter the trend of depoliticised scholarship in the face of increasing academic commercialisation ([81], p. 344). Second, it must be exceedingly sceptical with regard to concepts and methods that underpin (brain imaging) studies so as to identify flawed research (e.g. [102]). Slaby and Choudhury call for a 'confrontational response in cases of violation of scientific standards' ([81], p. 345). Such caution and calls for confrontation stem from concerns that humanities scholars and social scientists may become co-opted by their neuroscientific partners in light of power asymmetries and institutional dependencies. Slaby is 'doubtful indeed whether the humanities and social sciences will ever robustly benefit from interdisciplinary cooperation with 
experimental neuroscientists' since he considers 'most “third culture" ideas simply bunk' ([67], p. 3).

\section{Generative Critique in Experiments}

Critique that is neither overly detached and agonistic nor overly attached and morphed into uncritical service seems to be possible in an 'integrative-synthetic' mode of interdisciplinary collaboration ([75], p. 28). This mode of collaboration brings together disciplinary ways of thinking to advance knowledge in ways that would not have been possible through monodisciplinary means. However, Fitzgerald and Callard argue that the rhetoric of knowledge synthesis rests on the assumption that 'there is a thing called social science that addresses itself to one kind of objects; and there is a thing called neuroscience that addresses itself to another' ([46], $\mathrm{p}$. 15). This dichotomy renders invisible the 'rich archive of crossings' ([46], p. 16) blurring the boundaries between disciplines and objects. Psychology and neurology, for instance, are entangled because psyche, body, and environment form a mutually constitutive system from which no element emerges as origin to be studied in isolation [103]. Indebted to this stance, Fitzgerald and Callard propose that neuroscientific experiments can render these crossings fertile because experiments allow for 'digression and transgressions of smaller research units below the level of disciplines, in which knowledge has not yet become labelled and classified, and in which new forms of knowledge can take shape' ([104], p. 315). ${ }^{5}$ Fitzgerald and Callard refer to such open-ended experiments across the sociocultural-neurosciencedivide as 'experimental entanglements' ([46], p. 16). According to Niewöhner, experimental entanglements enable co-laboration and generative critique [49].

Experimental entanglements must be distinguished from the study of experimental practices in laboratory ethnography which focuses on 'critically' exposing underlying assumptions, interests, and constructions of scientific experiments [106-108]. As a number of STS scholars such as Lynch, Stengers, and Latour have pointed out, critical laboratory ethnographies often 'explain away' scientific practices by means of deconstruction [109-111]. Generative critique, by contrast,

\footnotetext{
${ }^{5}$ This conception of experiments stands in contrast with a plethora of STS research that demonstrates how experiments make nature fit to prior expectations and experimental apparatuses [105]. However, Fitzgerald and Callard draw on Rheinberger's ideal account of experiments as open processes that refuse preliminary decisions about outcomes.
}

appreciates perspectives and methods from experimental research. Humanities scholars and social scientists interfere in and with experimental spaces, materials, subjects, and instruments together with their neuroscientific partners. They collaborate by 'doing research together, using texts and tools together, analysing and writing together' ([49], p. 17; cf. [112]).

Fitzgerald and Callard present some of their own projects as experimental entanglements [46], which Niewöhner refers to as examples of generative critique ([49], p. 25, footnote 71). Fitzgerald conducted an experiment together with Littlefield and colleagues that connected neuroscientific assumptions about a biological correlate of deception, with a humanist tradition committed to the contingency of 'truth' and 'lie' [48]. By producing neuroimaging data that unsettled a neurobiological distinction between 'truth-telling' and 'deception', they transformed sociological and historical critique of neuroscientific assumptions into a meaningful collaboration. Callard directed the Hubbub project, which comprises several interdisciplinary projects, one of them on daydreaming [45]. To think beyond commonsensical assumptions about how people engage in and experience daydreaming, researchers with various disciplinary backgrounds worked together to pursue daydreaming as a phenomenon, construct, and tropea multiple object. Hubbub researchers developed new ways of investigating daydreaming by combining cultural, philosophical, sociological, psychological, and neuroscientific accounts.

More recent experimental entanglements establish an intersection of arts and sciences. Klein and Marghetis, an ethnographer of science and a cognitive scientist, draw on performance art and performance studies to create an 'experiment-performance' ([97], p. 17) that generates alternative ways of rethinking and remaking an experiment. In the conventional mode of contemporary psychological experiments, experimenters largely ignore participant feedback and keep all experimental conditions equal for each subject. By contrast, Klein and Marghetis remade their experimental design after each participant measurement in a way that responded to participant feedback. By remaking the experiment, they offer a generative critique of mainstream psychology research that casts responsiveness to study participants as epistemic threat [113]. Experimental entanglements that are currently taking shape involve collaborations with artists, such as the project 'Experimenting, Experiencing, Reflecting' (EER) and the Experiential 
Conference 'Touchy Subjects' in March 2020 in Denmark. EER is a collaboration between the Studio Olafur Eliasson in Berlin and the Interacting Minds Centre (IMC) at Aarhus University that develops open-ended experiments to explore perception, decision-making, action, collaboration, and knowledge transmission. ${ }^{6}$ The project calls for new forms of thought and action in response to contemporary environmental, political, and societal challenges. It enacts a generative critique of the status quo-'deep crises in trust and social cohesion' [114] - by making efforts to develop narratives and models for action to navigate the future in different ways. 'Touchy Subjects' seeks to critique a normativity of nontouch that dominates many contexts and relations by inquiring into multiple forms of encounter and their generation. For this purpose, the conference organised by the IMC and the Danish National School of Performing Art will bring together practitioners from performance, art, therapy, medicine, neuroscience, and other fields (www.touch-subjects.com).

The IMC directed by Roepstorff who works at the interface between the cognitive sciences, neurosciences, and anthropology is a space that invites experimental entanglements across disciplines and sectors. The centre hosts a range of affiliates as well as visiting scholars and researchers. They are invited to meet for breakfast, weekly seminars, and workshops while spending time together in an office space suffused with light and glass walls that facilitates collaboration among colleagues. ${ }^{7}$ However, it can take a long time until experimental entanglements emerge even if neuroscientists, humanities scholars, and social scientists share a room. Moreover, experimental entanglements do not come without difficulties. For example, Fitzgerald et al.'s experiment on 'truth-telling' and 'deception' was characterised by 'unspoken tension and lurking resentment' ([47], p. 707). Humanities scholars and social scientists questioned how the experiment could be fully collaborative although only one member of the group knew how to gather and analyse brain imaging data. Furthermore, the openendedness of their experimental entanglement gave rise to gaps between the original idea and the actual experiment. As the experimental design changed, 'so too, and not least for Littlefield, did an ambivalence form around

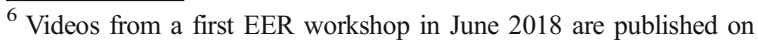
www.soe.tv/themes/experience.

${ }^{7}$ The author of this article visited the IMC in August 2019 to gain insights into how interdisciplinary research is initiated and facilitated in interdisciplinary centres and collectives.
}

whether the actual experiment lived up to the expectations of the idea or whether the final design was ultimately an experiment for experiment's sake' ([47], p. 708). Fitzgerald et al. conclude that such ambivalences are part of experimental entanglements, and that good collaboration depends on learning to live and work with ambivalence and reserve. To provide guidance for collaborating through ambivalence, Roepstorff is thinking about practices that could support the emergence and process of interdisciplinary collaboration and generative critique (personal communication, August 9, 2019). He emphasises that it is important to strike the right balance between structure and flexibility. The aim is to develop practices that open up and guide collaborative reflection and learning without formalising interactions in rigid structures that constrain rather than enable generative critique. Although generative critique has emerged organically in experimental entanglements spanning across the neurosciences, humanities, and social sciences, practices that support its emergence and unfolding still need to be put forward.

\section{Generative Critique in Interdisciplinary R(R)I Collaborations}

The case study of critique of and in the neurosciences demonstrates how generative critique has been enacted in neuroscientific experiments. However, generative critique in the neurosciences falls short of articulated practices that could be used across a variety of projects in support of generative critique in interdisciplinary collaboration. This gap could be filled with practices that have been developed to facilitate interdisciplinary $R(R) I$ collaborations. These practices range from constructive technology assessment [115], real-time assessment [116], visions and expectations assessment [117], techno-moral scenarios [118], to specific versions of stakeholder discussion groups [119]. ${ }^{8}$ However, they are widely acknowledged to face challenges, in particular a concern about taking a critical stance towards technoscientific practices that neither slips into agonism nor subordination [23-30]. Despite challenges, some practices have been recognised among scholars, policy-makers, scientists, engineers, and other professionals as 'effective' [120-123]. For these communities,

\footnotetext{
${ }^{8}$ The references serve as examples, for numerous authors have introduced, employed, and further developed these approaches.
} 
hallmarks of effectiveness are contributions to socially beneficial change in thought and actions in science, technology development, and related professional domains [124]. Among the practices that have been presented as effective in numerous publications are sociotechnical integration research (STIR) and videoreflexive ethnography (VRE). STIR has contributed to voluntary changes in science, engineering, businesses, and municipal energy supply initiatives. These changes concern research direction, experimental design, team work, and interactions with other stakeholders, to name but a few [55, 56, 125-130]. Similar proofs of effectiveness in healthcare have been achieved by VRE, for example, increased infection control [131], the development of an ambulance-to-emergency department handover protocol [132], greater commitment of nurses to palliative care [133], and optimisation of interprofessional communication [134]. That said, such effective practices are presumably but not necessarily appropriate for enacting generative critique.

STIR and VRE seem to align with generative critique because they have shown to elicit alternative ways of acting. However, the service-subordination mode of critique may be equally conducive to imagine and enact alternatives to the status quo. An example is change in healthcare that is initiated or reinforced by hospital consultants who collaborate with clinicians so as to serve a management agenda. ${ }^{9}$ To counter such objections, the following discussion will argue that STIR could be used as a practice of generative critique in interdisciplinary $\mathrm{R}(\mathrm{R}) \mathrm{I}$ collaborations in spite of limitations. Afterwards, VRE is introduced to develop suggestions for modifications of STIR so as to overcome its limitations in enacting generative critique. The discussion focuses on STIR because STIR is well-known in R(R)I communities whereas VRE is more established in healthcare research. VRE is a suitable supplement to rethink STIR because the practices resemble each other in key elements. They both involve open-ended collaborations between a humanities scholar or social scientist and other professionals. These collaborations involve regular sessions in which work routines are put up for discussion. The twofold aim is knowledge production about what goes into accomplishing these routines while stimulating reflections on how competences that often remain

\footnotetext{
${ }^{9}$ For a discussion on the distinction between 'uncritical' hospital consultancy and 'critical' engagement research, see Zuiderent-Jerak [42].
}

overlooked or courses of action that are taken as given could be enhanced. The following discussion shows that these elements are relevant for enacting generative critique in interdisciplinary $\mathrm{R}(\mathrm{R}) \mathrm{I}$ collaborations.

\section{Socio-Technical Integration Research (STIR)}

STIR was developed in response to the 21st Century Nanotechnology Research and Development Act of 2003 in the USA [135]. The Act required that 'research on societal concerns' was 'integrated with nanotechnology research and development' ([136], p. 117). To probe the capacities of nanotechnology researchers and engineers to integrate broader societal considerations into their work, Fisher developed a 12-week programme. He tested his programme in what became the first STIR pilot study in the Thermal and Nanotechnology Laboratory in Boulder, Colorado [55]. For this purpose, Fisher immersed himself as an 'embedded' scholar ([137], p. 216) in the laboratory where he interacted with numerous researchers, conducted interviews, participant observation, and archival research. Over the course of doing fieldwork, he noticed that researchers were often already integrating social and ethical concerns into their work without being aware of their own role in such a de facto integration. He discussed his insights with the researchers and assisted them in articulating further latent ethical reflections. To facilitate this process, he developed what he called the STIR 'decision protocol' ([138], p. 2). On the basis of the protocol, he engaged with researchers in a collaborative manner to map out their decision-making processes on a regular basis. They explored together how ethical and societal considerations were already or could be aligned with technical alternatives and how researchers could further cultivate or bring about this alignment in practice. As a result, researchers enhanced their capacities for integrating socio-ethical considerations with technical alternatives and started to perceive socio-technical integration as 'an integral part of th[eir] work' ([139], p. 74). In addition, they voluntarily altered their decisions and practices concerning experimental setup, material choice, and safety strategies [137]. Hence, the STIR pilot study realised a twofold agenda. On the one hand, it rendered research and innovation processes more akin to what would eventually be articulated as R(R)I by integrating societal and ethical considerations into these very processes and products. On the other hand, it resulted in knowledge production about whether such 
an integration is possible in the first place, about how it unfolds over time, and on how it co-produces ethics, science, and technology on the laboratory floor.

STIR serves as a practice for generative critique because it facilitates explorations of alternative ways of doing research in a collaborative learning process. By using participant observation as a resource for collaboration on issues of direct relevance to technoscientific practitioners, an embedded scholar avoids armchair critique. The collaborative nature of interactions helps circumvent a service-subordination mode of interdisciplinarity. Ethics cannot be 'outsourced' to an embedded scholar because what counts as 'ethical' and 'unethical' unfolds and may become altered over time in discussions about routine technoscientific practices. Each semi-structured dialogue guided by the decision protocol starts with exploring an opportunity, challenge, or problem that a researcher currently faces and that incites decision-making. A researcher and an embedded scholar co-develop a problem definition, reflect together on considerations that matter for alternative courses of action, and anticipate outcomes of a particular course of action selected from available alternatives [56]. The decision protocol structures interactions around four components (opportunity, considerations, alternatives, outcomes) but allows for flexibility in their order and application. While some embedded scholars adhere closely to the STIR decision protocol [127], others have altered or omitted components, choosing instead to adapt the STIR dialogue to their collaborators' concerns and needs [140]. STIR seems to strike a balance between structure and flexibility so that generative critique can emerge in the form of rethinking and remaking scientific and other opportunities, challenges, objects, and practices. The interaction between a scholar and a researcher from different disciplinary backgrounds allows for connecting and combining different ways of seeing and approaching a problem, for raising different questions about it, and for widening the horizon of considerations, values, and anticipated effects that play into a decisionmaking process. While a researcher may alter problem definitions, objectives, considerations, or practices on the basis of insights gained in a STIR dialogue, the embedded scholar may also modify her assumptions, questions, and conclusions about the laboratory environment, routine work, and its socio-ethical dimensions. Problem definitions, possible solutions, and insights evolve and change over the course of a STIR study. Mutual learning enables rethinking and remaking research and its objects - in short, generative critique.
Despite the outlined potential of STIR to enact generative critique in interdisciplinary $R(R) I$ collaborations, STIR could be further aligned with generative critique on three dimensions that studies informed by STIR have shown to be in need of improvement: the (1) affective, (2) collaborative, and (3) temporal dimension of interdisciplinarity [24, 28, 137, 140]. First, for Verran, a starting point in the pursuit of generative critique is cultivating sensitivity for moments in which epistemic and metaphysical differences can be experienced. Moments of 'disconcertment' ([50], p. 5) render sensible that tensions between different ways of making objects evoke immediate bodily responses, such as 'the sort of laughter that grows from seeing a certainty disrupted' ([60], p. 141). Affect may direct attention to otherwise overlooked differences, for instance, when meeting other academic disciplines' ways of capturing a problem and defining a research object [50]. However, STIR has so far not made use of the potential of affect to broaden ethical considerations and enact generative critique [140]. Second, studies inspired by STIR have shown that the realisation of collaboration in interdisciplinary teams is challenging [24, 28]. Embedded scholars may find themselves outside of scientists' and engineers' learning and decision-making processes for various reasons, including practical, cultural, and institutional barriers [124]. In light of asymmetric power relations and the possibility of 'cultural subversion', in which 'one party's language overwhelms that of the other' ([141], p. 660), embedded scholars run the risk to be cast as 'spokesperson for "ethics" ([137], p. 225). They may be expected to operate strictly as experts who evaluate courses of actions against ethical frameworks and give ethical advice. Such expectations may complicate a collaborative learning process. Third, aligning expectations and establishing trust between collaborators so as to invest in an open-ended process without clear outcomes may require time [140]. Whereas a STIR study is conducted within 12 weeks, Kenney describes 'how Verran-through decades of thoughtful participation - attunes her modes of attention, analysis, and narration' ([62], p. 750, emphasis added). Capabilities and conditions that allow for generative critique could be further nurtured over a longer period of time than the original STIR study design allows for. To enhance STIR's suitability as a practice for generative critique, video-reflexive ethnography could serve as a source of inspiration for modifications. 
Learning from Video-Reflexive Ethnography (VRE)

VRE is an engagement research method that was developed for health service research, evaluation, and improvement $[57,58]$. It encompasses two interrelated aims: academic research and optimisation of clinical practice. The main principle of VRE is that clinical practitioners, including physicians and nurses, view video footage of their everyday work. While watching fragments of their recorded work practices, they may see aspects of their work that have become opaque in daily routine. In regular 'video-reflexive sessions' ([142], p. 1145), clinical practitioners discuss these visualisations. Some of them have taken part in selecting video fragments to be shown to the group on the basis of criteria, such as level of visible detail, routine and exceptional cases, diversity of tasks, and relevance to the group. Viewing and discussing video material together create new ways of seeing and thinking about daily routines [143]. Clinical practitioners may become aware of their strengths and weaknesses and identify possibilities for improvement. AVRE researcher, often from the humanities or social sciences, facilitates this process not only by taking care of generating and selecting video material but also by moderating videoreflexive sessions. To complete these tasks, fieldwork is required to develop familiarity with what is going on at a particular healthcare site, the socio-historical context of the filmed material, and the institutional environment. Iedema and Carroll have coined the concept 'clinalyst' as a shorthand version of 'outsider-analyst-catalyst' ([144], p. 176) to refer to a VRE researcher who produces insider's knowledge by asking outsider's questions. A clinalyst opens up clinical practices to clinical practitioners, who, in return, open up their practices to the clinalyst. In a collaborative learning process, both gain access to latent practices that practitioners usually do not pay attention to or take as given. For example, Mesman used VRE to shed light on practices that ensure safety at a neonatal care ward [143]. Assuming that safety requires more than high technology, protocols, and training to avoid mistakes, Mesman focused on aspects of clinical work that go well and are safe. As these are hardly acknowledged or discussed by practitioners, Mesman used VRE to explicate practitioners' hidden competencies to understand the presence of safety in an environment marked by complex tasks and time rush.

VRE offers inspiration for refining STIR so as to align it further with generative critique with regard to the affective, collaborative, and temporal dimensions of interdisciplinarity. Verran's proposal to pay attention to affectively charged 'fleeting experiences' ([50], p. 5) has been taken up in VRE. The role of affect has first been highlighted in VRE studies as part of a clinical team's intelligence. According to Iedema et al., VRE 'highlights and reveals relationships in their affective aspects' ([58], p. 38), but the clinalyst remains an outsider who is not impacted in the affective fabric of these relationships. Later work has extended the importance of affect to the VRE researcher [145-147]. A VRE researcher who works with 'affect-as-method' ([142], p. 1148) develops sensitivity to affective dimensions of fieldwork and of video-reflexive sessions to detect moments of tension at the field site, in video footage, and in its group discussion. Paying attention to the experience of 'tacit or visceral impulses' ([142], p. 1150) may help identify tension between, for instance, rigid safety protocols on the one hand and the surprises and hectic of every day work on the other [148]. The ability to 'be moved' ([142], p. 1150) by what one encounters at the hospital may work as a driver for a VRE researcher and clinical practitioners to learn and act so as to accommodate tension in clinical practice [147]. Literature on VRE research that develops affect-as-method could help embedded scholars working with STIR to attend to and engage with the affective dimension of interdisciplinarity.

The methodological design of VRE could also serve as a model to modify STIR's collaborative dimension. Whereas STIR dialogues usually take place in a one-toone interaction, VRE is based on a group process involving nurses and physicians and sometimes even patients with their families join video-reflexive sessions facilitated by a VRE researcher (e.g. [131, 149]). In such a group process a range of concerns and viewpoints feed into a collaborative learning process across disciplines, sectors, and hierarchies (cf. [134]). Clinical practitioners' authority and patients' ownership over healthcare processes have shown to be perturbed by the video footage of these processes and by the opportunities, often created by the VRE researcher, 'for new questions to be asked, and new answers to be given, by all involved' ([144], p. 183). A VRE researcher avoids being treated as a moral decision guide by allowing clinical practitioners and patients to scrutinise her understandings and interpretations. VRE researchers have rather been casted as mediators between different interests and facilitators of 'reflective spaces' ([150], p. 203; [151], p. 33). Their task is to set reflective impulses and ensure the functioning of collective deliberation [152]. Similarly, embedded scholars could work with 
the STIR decision protocol to facilitate collective deliberation and unfold group decision-making in research teams. The decision protocol could either be used to reflect on an opportunity or problem that concerns all team members to various degrees, or an individual decision-making process could be discussed in the group. In this way, STIR could help establish reflective spaces where practices and positionings of team members are revisited and revised. This would allow research team members to recognise their colleagues' overlooked competencies and ethical reflections, learn from each other, critique each other in generative ways, and interact with an embedded scholar as a process facilitator, rather than as an ethics expert.

According to Iedema and Carroll, the role of a process facilitator who establishes and maintains reflective spaces needs to be institutionalised [144]. They consider a facilitator's long-term involvement as relevant for building capacities among clinical practitioners to deal with complex challenges of healthcare. Mesman, for instance, has collaborated with a neonatal intensive care ward for more than 20 years [143]. Over time, they built up a relationship of mutual trust and familiarity with each other's ambitions. Furthermore, her long-term involvement has enhanced her understanding of clinical practitioners' verbal and bodily language, which she considers as crucial for interpreting their responses to VRE. She learned to sense when and where filming was (in-)appropriate. She developed an affective sensitivity for subtle, fleeting moments of tension that someone unfamiliar with the ward may have overlooked. One may argue that decades of collaboration create such a high level of familiarity that moments of disconcertment stemming from epistemic difference between collaborators become rare. This may be a reason why other VRE studies only lasted between seven months and two years $[132,133]$. STIR studies could adjust their temporal dimension to such a time frame and investigate whether a longer duration of embeddedness is conducive for generative critique.

\section{Conclusion and Outlook}

Interdisciplinary R(R)I collaborations have embedded humanities scholars and social scientists in technoscientific spaces where they aim to both study and contribute to research and innovation processes. To pursue this double agenda, they must maintain critical distance so as to call these processes into question without operating on an epistemological meta-level that misses the issues at hand. This article demonstrates how humanities scholars and social scientists engaged in interdisciplinary collaborations with neuroscientists have managed to strike this balance by enacting generative critique in experimental entanglements [44-48, 97, 112]. Generative critique is a 'curiosity about the genealogies and the performativities of theories, concepts and methods used to represent [an object]' ([49], p. 13). It can emerge when attention is cultivated to the affective experience of differences between different ways of making an object, different ways of knowing, and different ways of being in the world [50]. Whereas the affective dimension of difference is hardly perceptible from an overtly removed position, a loss of critical distance renders differences invisible. Although humanities scholars and social scientists managed to take on a middle position in collaborations with neuroscientists, they shed light on the difficulties of adopting and maintaining it [47]. To overcome these difficulties and translate generative critique from the neurosciences to $\mathrm{R}(\mathrm{R}) \mathrm{I}$, a modified version of STIR that draws on insights from VRE could serve as a practice of generative critique in interdisciplinary $\mathrm{R}(\mathrm{R}) \mathrm{I}$ collaborations.

This proposal makes three contributions. First, it offers generative critique as a solution for the problem of taking on a 'critical' position in interdisciplinary collaborations that has concerned many humanities scholars and social scientists in R(R)I. To capture empirically how STIR enacts generative critique in interdisciplinary $R(R) I$ collaborations, an empirical project is currently in progress. This project is a prolonged two-phase STIR study in a neuroscientific clinical trial that investigates the impact of meditation in comparison to learning the English language on healthy ageing (www.silversantestudy.eu). The twofold objective of the project is to study and contribute to the integration of socio-ethical aspects in clinical research on meditation. In the first phase from September to December 2018, regular STIR dialogues took place with two $\mathrm{PhD}$ students in the neurosciences, a meditation instructor and an English language instructor who have been in charge of the study interventions. During this period, field notes were taken on the affective dimensions of participant observation, STIR dialogues, additional conversations, and on the personal affective experiences of the embedded scholar. ${ }^{10}$ Moreover, the question 'How do you feel about this opportunity/consideration/alternative/

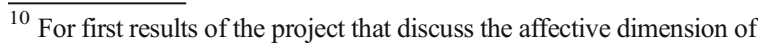
STIR, see [140].
} 
outcome?' was explicitly addressed in STIR dialogues to inquire into the affective dynamics that feed into ethical reflections and decision-making processes. ${ }^{11}$ In December 2018, a focus group was organised to explore how STIR could create a space for the research team to reflect on socio-ethical aspects of their work together. The embedded scholar facilitated the focus group discussion of an ethical challenge relevant to all team members by following the decision protocol and mapping their viewpoints, concerns, and suggestions for taking action. In the second phase of the project from October to December 2019, the embedded scholar conducted laboratory fieldwork in order to examine effects of the first phase. The temporal extension of STIR with a second phase of fieldwork, the organisation of a focus group, and the focus on affective dynamics in STIR dialogues and participant observation are modifications of STIR in reference to VRE. The empirical material will shed light on how this modified version of STIR enacts generative critique. For this purpose, the analysis will trace how the embedded scholar's positioning has evolved over time by focusing on shifts on the spectrum from armchair critique to loss of critical distance. Along these lines, both this article and the empirical project contribute to ongoing discussions on the dynamics of positioning in interdisciplinary collaborations in $R(R) I$ and in the engaged programme of STS more broadly.

The second contribution refers to the elaboration on critique, a notion that seems to be commonplace but unspecified in $\mathrm{R}(\mathrm{R}) \mathrm{I}$ discourses. The lack of specification has recently recurred in a discussion that took place in September 2019 in Leiden during the first event of a series of international symposia organised on the occasion of the launch of the International Handbook on Responsible Innovation. A Global Resource [153]. During the event, $\mathrm{R}(\mathrm{R}) \mathrm{I}$ was described as 'a new paradigm for innovation, that is both radically critical of and goes beyond previous (mainstream) paradigms of market innovation' ([154], emphasis added). For some, the qualifier 'radically critical' may invoke immediate associations with twentieth-century ideology critique, that is, a deconstruction of hegemonic narratives, such as mainstream paradigms of market innovation, to reveal their ideological and distorting character [155]. However, as the audience was filled with researchers who have a

\footnotetext{
${ }^{11}$ This question has been part of the initial STIR decision protocol [138], but published STIR studies have not addressed how reflections on the affective aspects of decision-making figure into decisionmaking processes.
}

background in STS, they probably rather think of Latour's diagnosis that ideology critique has 'run out of steam' and his plea for reconceptualising critique as unravelling the politics involved in making objects and facts [156]. These two conceptions of critique have diverging implications. Whereas ideology critique debunks and negates hegemonic narratives, Latour suggests to ask how the hegemonic has come into being and why it is reproduced - a blueprint for generative critique [49]. However, if we do not explicate what we mean when referring to 'critique', RI as a 'radically critical' paradigm remains ambiguous. This is problematic since $R(R) I$ communities aim to spread their programmes among policy-makers, scientists, engineers, other professionals, and wider publics who may not be familiar with discussions on critique in STS or in the humanities and social sciences more broadly. In pursuit of inclusivity and clarity in discussions on critique in $\mathrm{R}(\mathrm{R}) \mathrm{I}$, this article aims to resolve some ambiguity around the notion of critique. ${ }^{12}$

For this purpose, generative critique is delineated with a case study of critique of and in the neurosciences. By latching on discussions relevant for the neurosciences, this article makes a third contribution. It does not only translate generative critique from the neurosciences to R(R)I, but it also translates an approach to $R(R) I$ back to the neurosciences. It offers STIR adapted to elements from VRE to neuroscientists who share an interest in interdisciplinarity and look for practices that facilitate interdisciplinary collaborations. Interdisciplinary teams could use the STIR decision protocol as a group in order to facilitate collective decision-making on how to (re-)make an experiment that cuts across the neurosciences, humanities, and social sciences. The decision protocol could provide a structure for co-defining what counts as an experiment, exploring the considerations that matter for collaborators in its design, developing alternative versions to carry it out, and reflecting on possible experimental results as well as implications. As a result of the experiences with this practice, collaborators could refine it in order to best fit the team's needs. By means of such 'internal reengineering' [157], STIR supplemented by VRE could become a suitable practice of generative critique in collaborations across a variety of disciplines and sectors.

\footnotetext{
$\overline{12}$ Ibo van de Poel called for developing a language comprehensive for actors outside R(R)I circles during the event on 'Challenges for Responsible Innovation' on the 12th of September 2019 in Leiden that was attended by the author of this article.
} 
Acknowledgments I thank Cyrus Mody and Cornelius Borck for their support in the process of writing this article. I also thank Erik Fisher for instructing me on the STIR method and for feedback on draft manuscripts. I am grateful to Jessica Mesman for discussing her take on VRE with me and for her literature suggestions. Finally, I appreciate Christopher Coenen's encouragement to refine this article for publication.

Funding Information This article is published in the framework of the $\mathrm{PhD}$ research project 'The Meditating Brain in Context: An Exploration of Responsibility and Ethics in Action as an Engaged Ethnographer in Neuroscientific Meditation Research'. The project is funded for a period of three years by the German Academic Scholarship Foundation (Studienstiftung des Deutschen Volkes).

Open Access This article is licensed under a Creative Commons Attribution 4.0 International License, which permits use, sharing, adaptation, distribution and reproduction in any medium or format, as long as you give appropriate credit to the original author(s) and the source, provide a link to the Creative Commons licence, and indicate if changes were made. The images or other third party material in this article are included in the article's Creative Commons licence, unless indicated otherwise in a credit line to the material. If material is not included in the article's Creative Commons licence and your intended use is not permitted by statutory regulation or exceeds the permitted use, you will need to obtain permission directly from the copyright holder. To view a copy of this licence, visit http://creativecommons.org/licenses/by/4.0/.

\section{References}

1. Owen R, Pansera M (2018) Responsible innovation and responsible research and innovation. In: Simon D, Kuhlmann S, Stamm J, Canzler W (eds) Handbook on science and public policy. Edward Elgar, Cheltenham, pp 26-48

2. Brundage M, Guston DH (2019) Understanding the movement(s) for responsible innovation. In: Von Schomberg R, Hankins J (eds) International handbook on responsible innovation. A global resource. Elgar, Cheltenham, pp 102-121

3. Guston DH, Fisher E, Grunwald A, Owen R, Swierstra T, Van der Burg S (2014) Responsible innovation: motivations for a new journal. JRI 1(1):1-8

4. Owen R, Macnaghten P, Stilgoe J (2012) Responsible research and innovation: from science in society to science for society, with society. Sci Public Policy 39(6):751-760

5. Von Schomberg R (2013) A vision of responsible research and innovation. In: Owen R, Bessant J, Heintz M (eds) Responsible innovation: managing the responsible emergence of science and innovation in society. John Wiley \& Sons, Chichester, pp 51-74

6. Van Lente H, Swierstra T, Joly PB (2017) Responsible innovation as a critique of technology assessment. JRI 4(2):254-261

7. Rainey S, Stahl BC, Shaw M, Reinsborough M (2019) Ethics management and responsible research and innovation in the human brain project. In: Von Schomberg R, Hankins J (eds) International handbook on responsible innovation. A global resource. Elgar, Cheltenham, pp 379-392

8. Koops B-J (2015) The concepts, approaches, and applications of responsible innovation. In: Koops B-J, Oosterlaken I, Romijn H, Swierstra T, Van Den Hoven J (eds) Responsible innovation 2. Concepts, approaches and applications. Springer, Cham, pp 1-18

9. Fisher E (2018) Ends of responsible innovation. JRI 5(3): 253-256

10. Li F, Owen R, Simakova E (2015) Framing responsible innovation in synthetic biology: the need for a critical discourse analysis approach. JRI 2(1):104-108

11. Nordmann A, Schwarz A (2010) Lure of the 'yes': the seductive power of technoscience. In: Kaiser M, Kurath M, Maasen S, Rehmann-Sutter C (eds) Governing future technologies: nanotechnology and the rise of an assessment regime. Springer, Dordrecht, pp 255-278

12. Van Hove L, Wickson F (2017) Responsible research is not good science: divergences inhibiting the enactment of RRI in nanosafety. NanoEthics 11(3):213-228

13. Van Oudheusden M (2014) Where are the politics in responsible innovation? European governance, technology assessments, and beyond. JRI 1(1):67-86

14. Borck C (2018) Auf der Suche nach der verlorenen Kultur: Vom Neuroimaging über Critical Neuroscience zu Cultural Neuroscience - und zurück zur Kritik. Ber Wissenschaftsgesch 41:238-257

15. Thoreau F, Delvenne P (2012) Have STS fallen into a political void? Depoliticisation and engagement in the case of nanotechnologies. Polit Soc 11(20):205-226

16. Long TB, Blok V (2017) When the going gets tough, the tough get going: towards a new - more critical - engagement with responsible research and innovation in an age of Trump, Brexit, and wider populism. JRI 4(1):64-70

17. Klaassen P, Kupper F, Vermeulen S, Rijnen M, Popa E, Broerse J (2017) The conceptualization of RRI: an iterative approach. In: Asveld L, Van Dam-Mieras R, Swierstra T, Lavrijssen S, Linse K, Van Den Hoven J (eds) Responsible innovation 3. A European agenda?. Springer, Cham, pp 6992

18. De Jong M, Kupper F, Roelofsen A, Broerse J (2015) Exploring responsible innovation as a guiding concept: the case of neuroimaging in justice and security. In: Koops B-J, Oosterlaken I, Romijn H, Swierstra T, Van Den Hoven J (eds) Responsible innovation 2. Concepts, approaches and applications. Springer, Cham, pp 57-86

19. Royakkers L, Topolski A (2014) Military robotics \& relationality: criteria for ethical decision-making. In: Van Den Hoven J, Doorn N, Swierstra T, Koops B-J, Romijn H (eds) Responsible innovation 1. Innovative solutions for global issues. Springer, Dordrecht, pp 351-368

20. Blok V, Tempels T, Pietersma E, Jansen L (2017) Exploring ethical decision making in responsible innovation: the case of innovations for healthy food. In: Asveld L, Van DamMieras R, Swierstra T, Lavrijssen S, Linse K, Van Den Hoven J (eds) Responsible innovation 3. A European agenda?. Springer, Cham, pp 209-230

21. Lubberink R, Blok V, Van Ophem J, Omta O (2017) A framework for responsible innovation in the business 
context: lessons from responsible-, social- and sustainable innovation. In: Asveld L, Van Dam-Mieras R, Swierstra T, Lavrijssen S, Linse K, Van Den Hoven J (eds) Responsible innovation 3. A European agenda?. Springer, Cham, pp 181-208

22. Fisher E, O'Rourke M, Evans R, Kennedy EB, Gorman ME, Seager TP (2015) Mapping the integrative field: taking stock of socio-technical collaborations. JRI. https://doi. org/10.1080/23299460.2014.1001671

23. Aircardi C, Reinsborough M, Rose N (2017) The integrated ethics and society programme of the Human Brain Project: reflecting on an ongoing experience. JRI 5(1):125. https://doi.org/10.1080/23299460.2017.1331101

24. Åm H, Sørensen KH (2015) Preparing for new solar cells through integrated research: challenges in translating social robustness into the selection of materials. In: Bowman DM, Dijkstra A, Fautz C, Guivant J, Konrad K, Van Lente H, Woll S (eds) Practices of innovation and responsibility: insights from methods. Governance and action. AKA Verlag, Berlin, pp 181-195

25. Doubleday R, Viseu A (2010) Questioning interdisciplinarity: what roles for laboratory based social science? In: Lein Kjøolberg K, Wickson F (eds) Nano meets macro: social perspectives on nanoscale sciences and technologies. Pan Stanford, Stanford, pp 51-75

26. Rabinow P, Bennett G (2012) Designing human practices: an experiment with synthetic biology. The University of Chicago Press, Chicago

27. Rabinow P, Stavrianakis A (2013) Demands of the day: on the logic of anthropological inquiry. University of Chicago Press, Chicago

28. Thoreau F (2011) On reflections and reflexivity: unpacking research dispositifs. In: Zülsdorf TB, Coenen C, Fiedeler U, Ferrari A, Milbun C, Wienroth M (eds) Quantum engagements: social reflections of nanoscience and emerging technologies. IOS Press/AKA, Heidelberg, pp 219-235

29. Viseu A (2015) Caring for nanotechnology? Being an integrated social scientist. Soc Stud Sci 45(5):642-664

30. Nydal R (2015) Why is integration so difficult? Shifting roles of ethics and three idioms for thinking about science, technology and society. EiP 9(1):21-36

31. Sismondo S (2008) Science and technology studies and an engaged program. In: Hackett J, Amsterdamska O, Lynch M, Wajcman J (eds) The handbook of science and technology studies, 3rd ed. The MIT Press, Cambridge, pp 13-32

32. Fuller S (1993) Philosophy, rhetoric, and the end of knowledge: the coming of science and technology studies. University of Wisconsin Press, Madison

33. Fuller S (1997) Constructing the high church-low church distinction in STS textbooks. Bull Sci Technol Soc 17(4):181-183

34. Zuiderent-Jerak T, Jensen CB (2007) Editorial introduction: unpacking 'intervention' in science and technology studies. Sci as Cult 16(3):227-235

35. Caswill C, Shove E (2000) Introducing interactive social science. Sci Public Policy 27(3):154-157

36. Gjefsen MD, Fisher E (2014) From ethnography to engagement: the lab as a site of intervention. Sci as Cult 23(3): 419-431

37. Blok V (2019) From participation to interruption: toward an ethics of stakeholder engagement, participation and partnership in corporate social responsibility and responsible innovation. In: Von Schomberg R, Hankins J (eds) International handbook on responsible innovation. A global resource. Elgar, Cheltenham, pp 243-257

38. Markussen R, Olesen F (2007) Rhetorical authority in STSstudies of information technology: reflections on a study of implementation of IT at a hospital ward. Sci as Cult 16(3): 267-279

39. Mesman J (2007) Disturbing observations as a basis for collaborative research. Sci as Cult 16(3):281-295

40. Cole SA (2009) A cautionary tale about cautionary tales about intervention. Organ 16(1):121-141

41. Knobel C, Bowker GC (2011) Values in design. Commun ACM 54(7):26-28

42. Zuiderent-Jerak T (2015) Situated intervention: sociological experiments in health care. MIT Press, Cambridge

43. Mahfoud T (2014) Extending the mind: a review of ethnographies of neuroscience practice. Front Hum Neurosci 8(359). https://doi.org/10.3389/fnhum.2014.00359

44. Callard F, Fitzgerald D (2015) Rethinking interdisciplinarity across the social sciences and neurosciences. Palgrave Macmillan, New York

45. Callard F, Margulies DS (2014) What we talk about when we talk about the default network. Front Hum Neurosci 8(619). https://doi.org/10.3389/fnhum.2014.00619

46. Fitzgerald D, Callard F (2015) Social science and neuroscience beyond interdisciplinarity: experimental entanglements. Theory Cult Soc 32(1):3-32

47. Fitzgerald D, Littlefield MM, Knudsen KJ, Tonks J, Dietz MJ (2014) Ambivalence, equivocation and the politics of experimental knowledge: a transdisciplinary neuroscience encounter. Soc Stud Sci 44(5):701-721

48. Littlefield MM, Fitzgerald D, Knudsen KJ, Tonks J, Dietz MJ (2014) Contextualizing neuro-collaborations: reflections on a trans-disciplinary fMRI lie detection experiment. Front Hum Neurosci 8(149). https://doi.org/10.3389/fnhum.2014.00149

49. Niewöhner J (2016) Co-laborative anthropology. Crafting reflexivities experimentally. In: Jukka J, Tytti S (eds) Etnologinen tulkinta ja analyysi. Kohti avoimempaa tutkimusprosessia [ethnological interpretation and analysis: towards a transparent research process]. Ethnos, Helsinki. https://edoc.hu-berlin.de/bitstream/handle/18452 /19241/Niewoehner2016-Co-laborative-anthropology. pdf?sequence $=1 \&$ isAllowed $=y$

50. Verran H (2001) Science and an African logic. University of Chicago Press, Chicago

51. Hillersdal L, Jespersen AP, Oxlund B, Bruun B (2019) Affect and effect in interdisciplinary research collaboration. Sci Technol Stud. https://static-curis.ku.dk/portal/ files/212300703/Preprint_version_Hillersdal_et_al_ affect_and_effeef.pdf.

52. Butler J (2004) What is critique? An essay on Foucault's virtue. In: Salih S (ed) The Judith Butler reader. Blackwell, Oxford, pp 302-322

53. De Boer K, Sonderegger R (eds) (2012) Conceptions of critique in modern and contemporary philosophy. Palgrave Macmillan, New York

54. Gasché E (2007) The honor of thinking: critique, theory, philosophy. Stanford University Press, Stanford

55. Fisher E (2007) Ethnographic invention: probing the capacity of laboratory decisions. NanoEthics 1(2):155-165 
56. Fisher E, Schuurbiers D (2013) Socio-technical integration research: collaborative inquiry at the midstream of research and development. In: Doorn N, Schuurbiers D, Van de Poel I, Gorman ME (eds) Early engagement and new technologies: opening up the laboratory. Springer, Dordrecht, pp 97-110

57. Iedema R, Merrick E (2008) HELiCS: handover-enabling learning in communication for safety. Australian Commission on Safety and Quality in Health Care and the University of Technology, Sydney

58. Iedema R, Mesman J, Carroll K (2013) Visualising health care practice improvement: innovation from within. Radcliffe Publishing, London

59. Pels P (2008) What has anthropology learned from the anthropology of colonialism? Soc Anthropol 16(3):280299

60. Verran H (1999) Staying true to the laughter in Nigerian classrooms. Sociol Rev 47(1):136-155

61. Mol A (2002) The body multiple: ontology in medical practice. Duke University Press, Durham

62. Kenney M (2015) Counting, accounting, and accountability: Helen Verran's relational empiricism. Soc Stud of Sci 45(5):749-771

63. Rendtorff JD (2015) Case studies, ethics, philosophy, and liberal learning for the management profession. JME 39(1): 36-55

64. Littlefield MM (2017) "A mind plague on both your houses": imaging the impact of the neuro-turn on the neurosciences. In: Leefman J, Hildt E (eds) The human sciences after the decade of the brain. Elsevier, London, pp 198-213

65. Rose S (2003) The making of memory: from molecules to mind, 2nd ed. Vintage, London

66. Rose S (2012) The need for a critical neuroscience. From neuroideology to neurotechnology. In: Choudhury S, Slaby $\mathrm{J}$ (eds) Critical neuroscience: a handbook of the social and cultural contexts of neuroscience. Blackwell Publishing, West-Sussex, pp 53-66

67. Slaby J (2014) Rezensionen. Nikolas Rose, Joelle M. AbiRached, Neuro: the new brain sciences and the management of the mind. Ber Wissenschaftsgesch 37:1-3

68. Matusall S (2012) Looking for the social in the brain: the emergence of neuroscience. ETH Zürich, Zürich

69. Rose N (2010) 'Screen and intervene': governing risky brains. Hist Hum Sci 23(1):79-105

70. Dumit J (2004) Picturing personhood: brain scans and biomedical identity. Princeton University Press, Princeton

71. Abbott A (2009) Brain imaging studies under fire: social neuroscientists criticized for exaggerating links between brain activity and emotions. Nature 457:245

72. Joel D (2011) Male or female? Brains are intersex. Front Integr Neurosci 5(57). https://doi.org/10.3389/fnint.2011.00057

73. Joel D, Fausto-Sterling A (2016) Beyond sex differences: new approaches for thinking about variation in brain structure and function. Philos Trans R Soc B 371:20150451

74. Joel D, Persico A, Salhov M, Berman Z, Oligschläger S, Meilijson I, Averbuch A (2018) Analysis of human brain structure reveals that the brain "types" typical of males are also typical of females, and vice versa. Front Hum Neurosci 12(399). https://doi.org/10.3389/fnhum.2018.00399

75. Barry A, Born G, Weszkalnys G (2008) Logics of interdisciplinarity. Econ Soc 37(1):20-49
76. Choudhury S, Slaby J (eds) (2012) Critical neuroscience: a handbook of the social and cultural contexts of neuroscience. Wiley-Blackwell, London

77. Littlefield MM, Johnson JM (eds) (2012) The neuroscientific turn. Transdisciplinarity in the Age of the Brain. The University of Michigan Press, Ann Arbor

78. Pickersgill M, Van Keulen I (eds) (2011) Sociological reflections on the neurosciences. Emerald, Bingley

79. Ortega F, Vidal F (2011) Neurocultures: glimpses into an expanding universe. Peter Lang, Frankfurt am Main

80. Rose N, Abi-Rached JM (2013) Neuro. The new brain sciences and the management of the mind. Princeton University Press, Princeton

81. Slaby J, Choudhury S (2017) Proposal for a critical neuroscience. In: Meloni M, Cromby J, Fitzgerald D, Lloyd S (eds) The Palgrave handbook of biology and society. Palgrave Macmillan, London, pp 341-371

82. Hartmann M (2012) Against first nature. Critical theory and neuroscience. In: Choudhury S, Slaby J (eds) Critical neuroscience: a handbook of the social and cultural contexts of neuroscience. Blackwell Publishing, West-Sussex, pp 67-104

83. Choudhury S, Slaby J (2012) Introduction. Critical neuroscience - between lifeworld and laboratory. In: Choudhury S, Slaby J (eds) Critical neuroscience: a handbook of the social and cultural contexts of neuroscience. Blackwell Publishing, West-Sussex, pp 1-26

84. Raz A (2012) Critical neuroscience: from neuroimaging to tea leaves in the bottom of a cup. In: Choudhury S, Slaby J (eds) Critical neuroscience: a handbook of the social and cultural contexts of neuroscience. Wiley-Blackwell, London, pp 265-272

85. Slaby J (2010) Steps towards a critical neuroscience. Phenomenol Cognit Sci 9:397-416

86. Choudhury S, Nagel SK, Slaby J (2009) Critical neuroscience: linking neuroscience and society through critical practice. BioSocieties 4:61-77

87. Marks JH (2010) A neuroskeptic's guide to neuroethics and national security. AJOB Neurosci 1:4-12

88. Fitzgerald D, Matusall S, Skewes J, Roepstorff (2014) What's so critical about critical neuroscience? Rethinking experiment, enacting critique. Front Hum Neurosci 8: 365. https://doi.org/10.3389/fnhum.2014.00365

89. Slaby J, Choudhury S (2012) Proposal for a critical neuroscience. In: Choudhury S, Slaby J (eds) Critical neuroscience: a handbook of the social and cultural contexts of neuroscience. Wiley-Blackwell, London, pp 27-51

90. Mòdol I Vidal L (2011) Review of Ortega and Vidal (Eds.) (2011). Neurocultures: glimpses into an expanding universe. Quaderns de Pscicologia 13(2): 81-82

91. De Vos J, Pluth E (eds) (2016) Neuroscience and critique. Exploring the limits of the neurological turn. Routledge, London

92. Leefmann J, Hildt E (eds) (2017) The human sciences after the decade of the brain. Elsevier, London

93. Vidal F, Ortega F (2017) Being brains. Making the cerebral subject. Fordham University Press, New York

94. Leefmann J, Hildt E (2017) Introduction. In: Leefmann J, Hildt E (eds) The human sciences after the decade of the brain. Elsevier, London, pp xi-xix

95. Massumi B (1995) The autonomy of affect. Cult Critique $31: 83-110$ 
96. Lysen F (2019) Performing patterns: investigating artscience collaboration at the Maastricht brain stimulation and cognition group. Bias in $\mathrm{AI}$ and neuroscience. Transdisciplinary conference, June 17-19, Radboud University, Nijmegen, pp 64-70

97. Klein S, Marghetis T (2017) Shaping experiment from the inside out: performance-collaboration in the cognitive science lab. Perform Matters 3(2):16-40

98. McConachie B (2010) Preface. In: McConachie B, Hart FE (eds) Performance and cognition: theatre studies and the cognitive turn. Routledge, London, $\mathrm{pp} \mathrm{ix}-\mathrm{xv}$

99. Blair R (2008) The actor, image, and action: acting and cognitive neuroscience. Routledge, London

100. Littlefield MM, Johnson JM (2012) Introduction: theorizing the neuroscientific turn - critical perspectives on a translational discipline. In: Littlefield MM, Johnson JM (eds) The neuroscientific turn. Transdisciplinarity in the age of the brain. The University of Michigan Press, Ann Arbor, pp 1-25

101. Cooper M (2016) Life as surplus: biotechnology and capitalism in the neoliberal era. Galmuri Press, Seoul, Korean Translation

102. Haueis P (2014) Meeting the brain on its own terms. Front Hum Neurosci 8(815). https://doi.org/10.3389 /fnhum.2014.00815asahajsjs

103. Wilson EA (2004) Psychosomatic: feminism and the neurological body. Duke University Press, Durham

104. Rheinberger HJ (2011) Consistency from the perspective of an experimental systems approach to the sciences and their epistemic objects. Manuscrito 34(1):307-321

105. Sismondo S (2010) The social construction of scientific and technical realities. In: An introduction to science and technology studies, 2nd ed. Blackwell Publishing Ltd, West Sussex, pp 57-71

106. Langlitz N (2012) Neuropsychedelia: the revival of hallucinogen research since the decade of the brain. University of California Press, Berkeley

107. Lindemann G (2009) From experimental interaction to the brain as the epistemic object of neurobiology. Hum Stud 32:153-181

108. Mahfoud T (2018) Blue skies and glimmering stars. Visions of the human brain project. Dissertation, King's College London

109. Ziewitz M, Lynch M (2018) It's important to go to the laboratory: Malte Ziewitz talks with Michael Lynch. Engag Sci Technol Soc 4:366-385

110. Stengers I (2000) Invention of modern science. University of Minnesota Press, Minneapolis

111. Latour B (2004) Why has critique run out of steam? From matters to fact to matters of concern. Crit Inq 30(2):225-248

112. Roepstorff A, Frith CD (2012) Neuroanthropology or simply anthropology? Going experimental as method, as object of study, and as research aesthetic. Anthropol Theory 12(1): 101-111

113. Danziger K (1994) Constructing the subject: historical origins of psychological research. Cambridge University Press, Cambridge

114. Roepstorff A (2019) Experimenting, experiencing, reflecting art and science at work in the public realm. Carlsbergfondets "Semper Ardens" forskningsprojekter.
https://www.carlsbergfondet.dk/da/Forskningsaktiviteter/ Bevillingsstatistik/BevillingsBevillin/CF18_1111 Andreas-Roepstorff .

115. Rip A, Van Lente H (2013) Bridging the gap between innovation and ELSA: the TA program in the Dutch Nano-R\&D Program NanoNed. NanoEthics 7(1):7-16

116. Guston DH, Sarewitz D (2002) Real-time technology assessment. Technolog Soc 24(1-2):93-109

117. Lucivero F, Swierstra T, Boenink M (2011) Assessing expectations: towards a toolbox for an ethics of emerging technologies. NanoEthics 5(2):129-141

118. Arnaldi S (2018) Retooling techno-moral scenarios. A revisited technique for exploring alternative regimes of responsibility for human enhancement. NanoEthics 12(3): 283-300

119. Zwart H, Brenninkmeijer J, Eduard P, Krabbenborg L, Laursen S, Revuelta G, Toonders W (2017) Reflection as a deliberative and distributed practice: assessing neuroenhancement technologies via mutual learning exercises (MLEs). NanoEthics 11(2):127-138

120. Gorman ME, Groves JF, Shrager J (2004) Societal dimensions of nanotechnology as a trading zone: results from a pilot project. In: Baird D, Nordmann A, Schummer J (eds) Discovering the nanoscale. IOS Press, Amsterdam, pp 63-77

121. Krabbenborg L (2013) Dramatic rehearsal on the societal embedding of the lithium chip. In: Van der Burg S, Swierstra T (eds) Ethics on the laboratory floor. Palgrave Macmillan, New York, pp 168-183

122. Ribes D, Baker G (2007) Modes of social science engagement in community infrastructure design. In: Steinfield C, Pentland BT, Ackermann M, Contractor N (eds) Communities and technologies 2007: proceedings of the third communities and technologies conference, Michigan State University, 2007. Springer, London, pp 107-130

123. Shilton $\mathrm{K}$ (2014) Values levers: building ethics into design. Sci Technol Hum Values 38(3):374-397

124. Fisher E (2019) Engaging the micro-foundations of responsible innovation: integration of social sciences and humanities with research and innovation practices. In: Von Schomberg R, Hankins J (eds) International handbook on responsible innovation. A global resource. Elgar, Cheltenham, pp 194-210

125. Fisher E, Biggs S, Lindsay S, Zhao J (2010) Research thrives on integration of natural and social sciences. Nature 463(7284): 1018

126. Schuurbiers D (2011) What happens in the lab: applying midstream modulation to enhance critical reflection in the laboratory. Sci Eng Ethics 17(4):769-788

127. Flipse SM, Van der Sanden MC, Osseweijer P (2014) Improving industrial R\&D practices with social and ethical aspects: aligning key performance indicators with social and ethical aspects in food technology R\&D. Technol Forecast Soc Change 85:185-197. https://doi.org/10.1016 j.techfore.2013.08.009

128. Lukovics M, Fisher E (2017) Socio-technical integration research in an eastern European setting: distinct features, challenges and opportunities. Soc Eco 39(4):501-528

129. Flipse SM, Van de Loo CJ (2018) Responsible innovation during front-end development: increasing intervention capacities for enhancing project management reflections on complexity. JRI 5(2):225-240 
130. Richter JA, Tidwell ASD, Fisher E, Miller TR (2015) STIRring the grid: engaging energy systems design and planning in the context of urban sociotechnical imaginaries. Innovation: The European Journal of Social Science Research 30(3):365-384

131. Wyer M, Jackson D, Iedema R, Hor S-Y, Gilbert GL, Jorm C, Hooker C, O'Sullivan MVN, Carroll K (2015) Involving patients in understanding hospital infection control using visual methods. J Clin Nurs 24:1718-1729. https://doi.org/10.1111/jocn.12779

132. Iedema R, Ball C, Daly B, Young J, Green T, Middleton P, Foster-Curry C, Jones M, Hoy S, Comerford D (2012) Design and evaluation of a new ambulance-to-ED handover protocol: 'IMIST-ABO'. BMJ Qual Saf 21:627-633

133. Collier A, Hodgins M, Crawford G, Every A, Womsley K, Jeffs C ... Dadich A (2018) What does it take to deliver brilliant home-based palliative care? Using positive organisational scholarship and video reflexive ethnography to explore the complexities of palliative care at home. Palliative Med. https://doi.org/10.1177/02692163188 07835

134. Carroll K, Mesman J, McLeod H, Boughey J, Keeney G, Habermann E (2018) Seeing what works: identifying and enhancing successful interprofessional collaboration between pathology and surgery. J Interprof Care. https://doi. org/10.1080/13561820.2018.1536041

135. Fisher E (2019) Governing with ambivalence: the tentative origins of socio-technical integration. Res Policy 48(5): $1138-1149$

136. US Congress (2003) 21st Century Nanotechnology Research and Development Act. $108^{\text {th }}$ Congress Public Law, pp 108-153

137. Fisher E, Mahajan RL (2010) Embedding the humanities in engineering: art, dialogue, and a laboratory. In: Gorman ME (ed) Trading zones and interactional expertise: creating new kinds of collaboration. MIT Press, Cambridge, pp 209-230

138. Fisher E (2018) Socio-technical integration research (STIR) manual. Unpublished manuscript

139. Fisher E, Maricle G (2014) Higher-level responsiveness? Socio-technical integration within US and UK nanotechnology research priority setting. Sci Public Policy 42(1):72-85

140. Smolka M, Fisher E, Hausstein A (2019) From affect to action: STIRring up interdisciplinary collaborations. Unpublished manuscript

141. Collins H, Evans R, Gorman M (2007) Trading zones and interactional expertise. Stud Hist Phil Sci 38:657-666

142. Carroll K, Mesman J (2018) Multiple researcher roles in video-reflexive ethnography. Qual Health Res 28(7):11451156

143. Mesman J (2015) Boundary-spanning engagements on a neonatal ward: reflections on a collaborative entanglement between clinicians and a researcher. In: Penders B, Vermeulen N, Parker J (eds) Collaboration across health research and medical care: healthy collaboration. Ashgate, Surry, pp 171-194

144. Iedema R, Carroll K (2011) The 'clinalyst': institutionalising reflexive space to realise safety and flexible systematisation in health care. J Organ Change Manag 24(2): $175-190$

145. Collier A (2013) Deleuzians of patient safety: a videoreflexive ethnography of end-of-life care. University of Technology, Sydney, Dissertation

146. Iedema R, Carroll K (2015) Research as affect-sphere: towards spherogenics. Emot Rev 7:67-72. https://doi. org/10.1177/1754073914544477

147. Wyer M, Iedema R, Hor S, Jorm C, Hooker C, Gilbert G (2017) Patient involvement can affect clinicians' perspectives and practices of infection prevention and control: a "post-qualitative" study using video-reflexive ethnography. Int J Qual Methods 16:1-10. https://doi.org/10.1177 /1609406917690171

148. Mesman J, Hor S-Y (2018) Sticky business: techniques to engage with the viscosity of practices in healthcare. Paper presented at EASST conference, Lancaster, 25-28 July

149. Collier A, Wyer M (2016) Researching reflexively with patients and families: two studies using videoreflexive ethnography to collaborate with patients and families in patient safety research. Qual Health Res 26(7):979-993

150. Dzur A (2002) Democratizing the hospital: deliberativedemocratic bioethics. J Health Politics Policy Law 27(2):89-98

151. Walker MU (1993) Keeping moral space open: new images of ethics consulting. Hast Cent Rep 23(3):33-40

152. Mesman J, Walsh K, Kinsman L, Ford K, Bywaters D (2019) Blending video-reflexive ethnography with solution-focused approach: a strength-based approach to practice improvement in health care. Int J Qual Methods 18:1-10. https://doi.org/10.1177/1609406919875277

153. Von Schomberg R, Hankins J (eds) (2019) International handbook on responsible innovation. A global resource. Elgar, Cheltenham

154. Von Schomberg L (2019) Challenges for responsible innovation. Selected highlights from the discussion. Leiden University, 12 September. https://app.box.com/s/mh0k68 p9bjo3oqatuszeez0bvw7idyjb

155. Sankaran K (2019) What's new in the new ideology critique? Philos Stud:1-22. https://doi.org/10.1007/s11098019-01261-9

156. Latour B (2004) Why has critique run out of steam? From matters to fact to matters of concern. Crit Inq 30(2):225-248

157. Carise D, Cornely W, Gurel O (2002) A successful researcher-practitioner collaboration in substance abuse treatment. J Subst Abus Treat 23:157-162

Publisher's Note Springer Nature remains neutral with regard to jurisdictional claims in published maps and institutional affiliations. 